Available online on 15.05.2017 at http://iddtonline.info
(2011-17, publisher and licensee JDDT, This is an Open Access article which permits unrestricted
non-commercial use, provided the original work is properly cited

Review Article

\title{
DERMATITIS: A GROUP OF SKIN DISEASES
}

\author{
Hemant K. Nagar*, Mahendra S. Ranawat \\ Bhupal Nobles' College of Pharmacy, Udaipur-313002, India
}

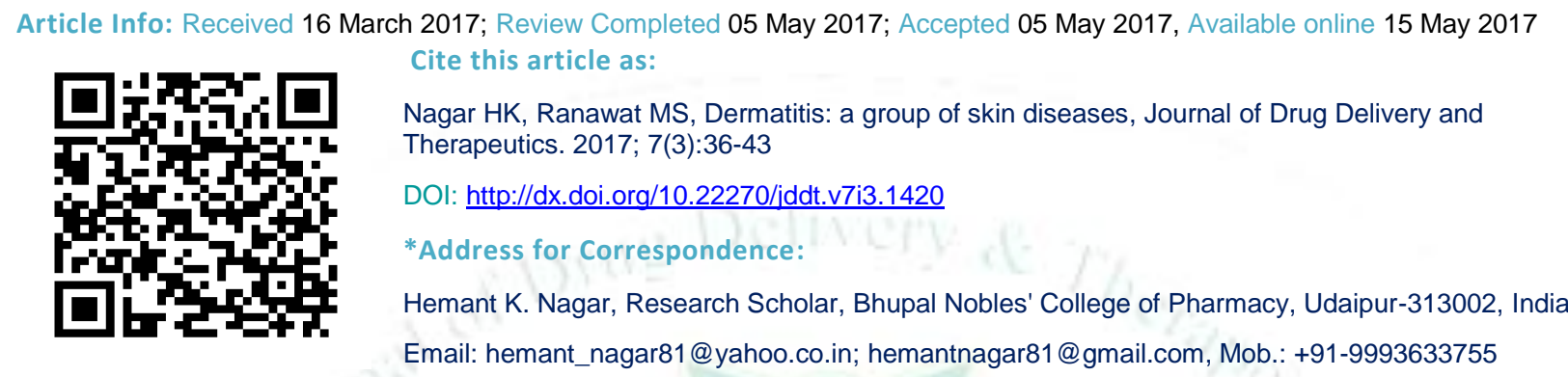

\begin{abstract}
Dermatitis is a group of skin conditions that includes atopic dermatitis, allergic contact dermatitis, irritant contact dermatitis and stasis dermatitis. The exact cause of dermatitis is often unclear. Dermatitis symptoms vary with all different forms of the condition. They range from skin rashes to bumpy rashes or including blisters. Although every type of dermatitis has different symptoms, there are certain signs that are common for all of them, including redness of the skin, swelling, itching and skin lesions with sometimes oozing and scarring. Also, the area of the skin on which the symptoms appear tends to be different with every type of dermatitis, whether on the neck, wrist, forearm, thigh or ankle. Topical immunosuppressants like pimecrolimus and tacrolimus may be better in the short term and appear equal to steroids after a year of use. Light therapy using ultraviolet light has tentative support but the quality of the evidence is not very good. Most cases are well managed with topical treatments and ultraviolet light.
\end{abstract}

Key Words: Dermatitis, allergic contact dermatitis, irritant contact dermatitis

\section{INTRODUCTION}

There is a wide range of dermatological conditions that include inflammatory skin disorders ranging in severity from mild skin rash to severe dermatitis ${ }^{1}$. Dermatitis describes a specific type of inflammation of the skin. Contact dermatitis (CD) describes inflammation which is caused by contact with something in the environment 2 .

Acute Contact Dermatitis: Acute CD is characterized by redness, papules (bumps) and vesicles. The appearance of small 1-3 mm vesicles and occasionally bullae is the hallmark of allergic contact dermatitis. Itching is often intense and may disrupt sleep.

Subacute Contact Dermatitis: Subacute CD is characterized by redness and itching but vesicles are seen as fine peeling, scale or a thickening of the skin. Itching continues and scratching causes small sores or excoriations. Linear fissures or cracks are common at sites of mechanical trauma, especially on the hands.

Chronic Contact Dermatitis: Chronic CD is minimally red or inflamed and is characterized by thickened skin that is scaling or shiny on the surface with cracking and fissuring at sites where skin is stretched by motion. Burning and pain of the fissures is more a complaint at this stage than itching.

Contact dermatitis represents a non-specific dermal reaction to direct action of an irritant or an allergen. It includes both Allergic and Irritant Contact Dermatitis as distinct entities. Within Irritant Contact Dermatitis there are several subtypes. $\mathrm{CD}$ is one of the most common skin diseases, with a lifetime prevalence of between 1$10 \%$ in industrialized societies ${ }^{3}$. CD is characterized by a chronic course with relapses upon contact with allergens or irritants. Management is complicated by 
lack of effective and reliable diagnosis. There is no cure for $C D$. CD represents the most common cause of occupational skin diseases in industrial countries and therefore is of major importance in occupational medicine ${ }^{4}$.

Two causes of contact dermatitis are exposure to allergens and irritants. An allergy occurs when the immune system reacts to a chemical. An irritant can be a strong soap or chemical.

Exposure to allergens and irritants frequently occurs in the workplace.

An allergy causes contact dermatitis in two ways:
- Contact urticaria - the immediate appearance of hives (transient itchy swellings).

- Allergic contact dermatitis - chronic areas of itchy, red, crusty or scaly skin.

Irritant contact dermatitis is produced by repeated exposure to a harsh or drying chemical that damages the outer skin barrier. Damage can be:

- Acute (sudden and quick) after contact with a high concentration of a chemical that sets off a reaction such as a burn.

- Chronic (persistent) or delayed (when it occurs after months or years of contact with an irritant).

Table 1: Some Irritants and Allergens found in many jobs 5

\begin{tabular}{|c|c|c|}
\hline Jobs & Irritants & Allergens \\
\hline Agriculture workers & $\begin{array}{l}\text { Artificial fertilizers, disinfectants, } \\
\text { pesticides, cleaners, gasoline, diesel oil, } \\
\text { plants and grains }\end{array}$ & $\begin{array}{l}\text { Rubber, oats, barley, animal feed, veterinary } \\
\text { medications, cement, plants, pesticides, wood } \\
\text { preservatives }\end{array}$ \\
\hline $\begin{array}{l}\text { Cabinet makers and } \\
\text { carpenters }\end{array}$ & $\begin{array}{l}\text { Glues, detergents, thinners, solvents, } \\
\text { wood preservatives }\end{array}$ & $\begin{array}{l}\text { Stains, glues, woods, turpentine, varnishes, } \\
\text { colophony }\end{array}$ \\
\hline Construction workers & Cement & $\begin{array}{l}\text { Chromates, cobalt, rubber and leather gloves, } \\
\text { resins, woods }\end{array}$ \\
\hline Day care workers & Detergents, cleaners, wet work & \\
\hline $\begin{array}{l}\text { Dentists and dental } \\
\text { technician }\end{array}$ & Detergents, hand cleansers, wet work & $\begin{array}{l}\text { Local anaesthetics, mercury, methacrylates, } \\
\text { eugenol, disinfectants, rubber, dental } \\
\text { impression material }\end{array}$ \\
\hline Electricians & Soldering fluxes & Fluxes, resins, rubber \\
\hline Hairdressers & $\begin{array}{l}\text { Permanent wave solutions, shampoos, } \\
\text { bleaching agents, wet work }\end{array}$ & Dyes, persulphates, nickel, perfumes, rubber \\
\hline Homemakers & Detergents, cleansers, foods, wet work & $\begin{array}{l}\text { Rubber gloves, foods, spices, flavours, nickel, } \\
\text { chromates, polishes }\end{array}$ \\
\hline Mechanics & $\begin{array}{l}\text { Oils, greases, gasoline, diesel fuel, } \\
\text { cleaners, solvents }\end{array}$ & $\begin{array}{l}\text { Rubber gloves, chromates, epoxy resin, } \\
\text { antifreeze }\end{array}$ \\
\hline $\begin{array}{l}\text { Medical personnel, } \\
\text { nurses, Hospital workers }\end{array}$ & Disinfectants, detergents, wet work & $\begin{array}{l}\text { Latex gloves, anaesthetics, antibiotics, } \\
\text { antiseptics, phenothiazines, formaldehyde, } \\
\text { glutaraldehyde, liquid chloroxylenol, hand } \\
\text { creams }\end{array}$ \\
\hline Plastic workers & Solvents, acids, styrene, oxidizing agents & $\begin{array}{l}\text { Hardeners, phenolic resins, polyurethanes, } \\
\text { acrylics, plasticizers }\end{array}$ \\
\hline Teachers & Chalk dust & \\
\hline
\end{tabular}

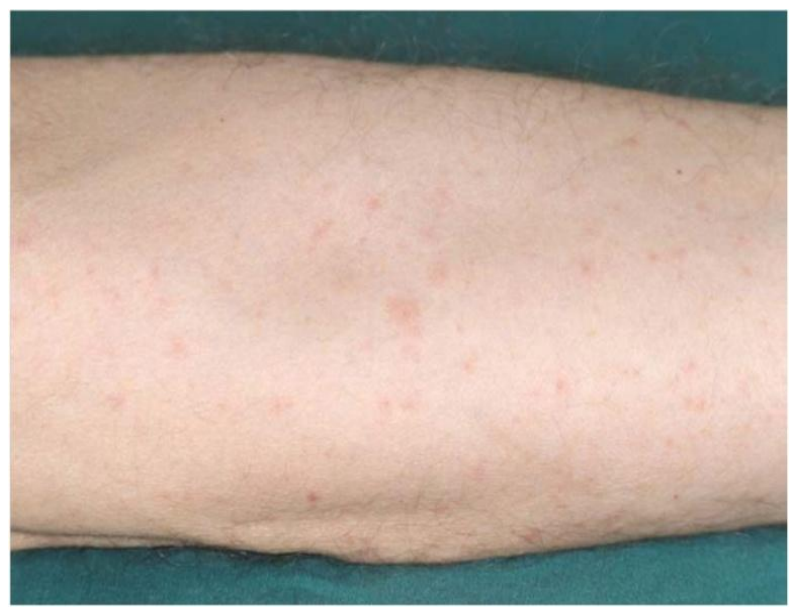

Figure 1: Glass fiber dermatitis- Severe itchy small papules on the forearms

\section{IRRITANT CONTACT DERMATITIS (ICD)}

ICD can be defined as a non-immunological, nonspecific reaction of the skin to an irritant. It is now recognized that this definition is too simplistic. New evidence does suggest that our immune system plays a role in eliciting ICD, via multiple parallel pathways ${ }^{6}$. In essence an irritant cause's toxicity or damage to epidermal skin cells which results in inflammation by natural immunity. Natural immune responses comprise of cells or mechanisms that defend a person from infection or damage, in a non-specific manner. The response to damage or infection is nonspecific and this immune response does not confer long-lasting or protective immunity to the host. There is some evidence that endogenous (genetic predisposition) factors influence the susceptibility to ICD. These include age, sex, anatomic site and history of eczema including 
atopic (genetic) eczema. Susceptibility to irritation decreases with age, and is more common in women and on the face.

\section{Types of $\mathrm{ICD}^{7}$}

There are 10 subtypes of Irritant Contact Dermatitis

(i) Acute Irritant Contact Dermatitis: Acute ICD is caused by exposure to a potent irritant such as a strong acid or alkali. The skin response includes erythema (redness of the skin due to capillary dilatation), edema and possible necrosis (death) of skin cells. This occurs very soon after exposure. The healing occurs rapidly after the exposure and often takes up to 4 weeks. The prognosis is very good but scarring can occur. An example would be exposure to wet cement causing a "cement burn".

(ii) Delayed Acute Irritant Contact Dermatitis: Some chemicals, such as dithranol and benzalkonium chloride, have the potential to cause a delayed inflammatory response, approximately 8-24 hours following the initial exposure $^{\mathbf{8}}$. The symptoms are similar to acute ICD, and the prognosis is good. It is important to have knowledge of this subtype as the delayed nature of the dermatitis may lead the clinician to misinterpret the eruption as ACD.

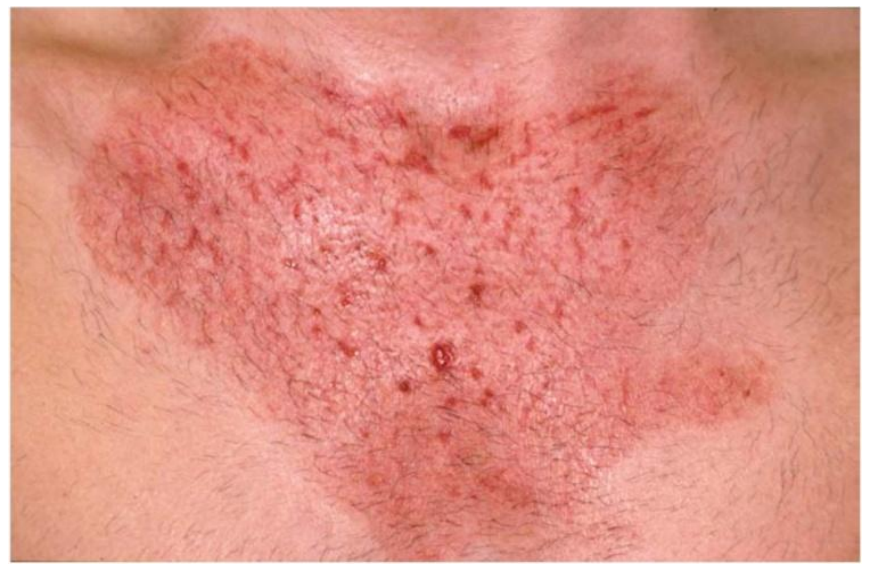

Figure 2: Acute irritant contact dermatitis
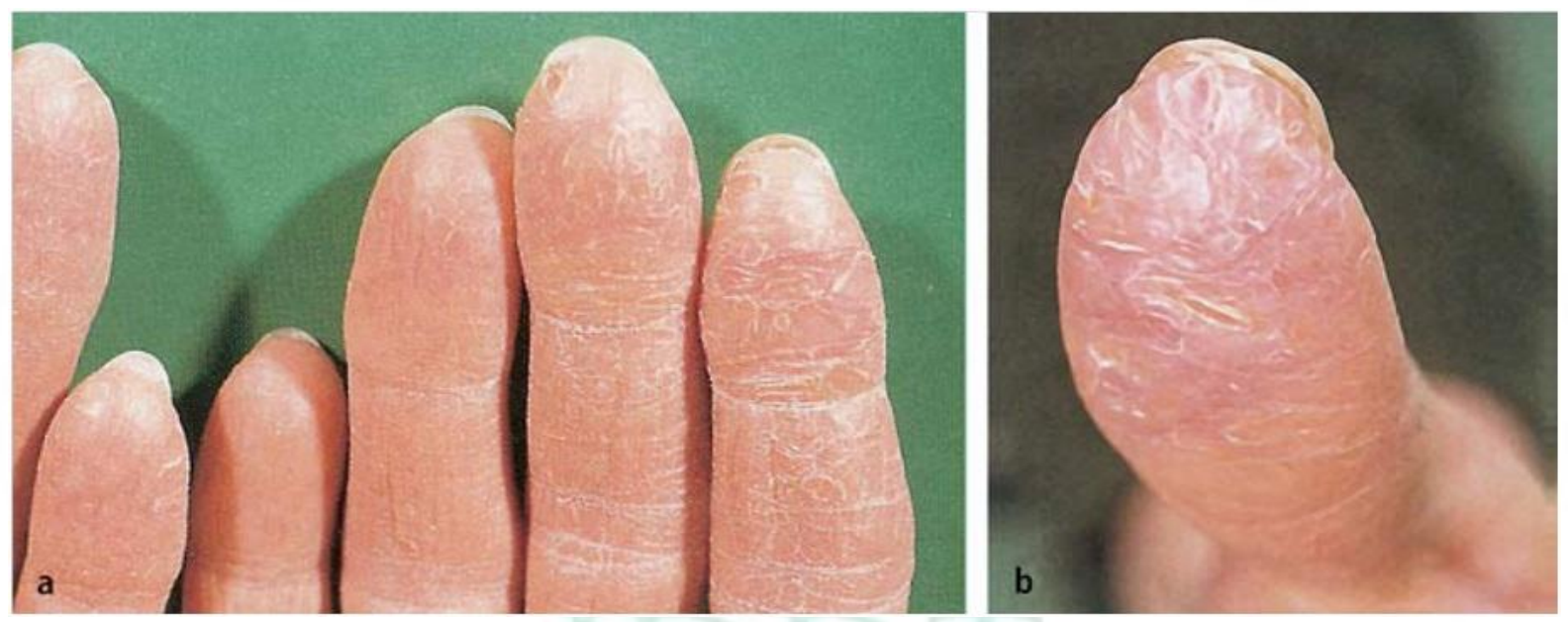

Figure 3: Chronic irritant contact dermatitis (cumulative insult dermatitis). (a) Housewife's eczema due to wet work and a number of irritants. (b) Close-up view of the thumb

(iii) Irritant Reaction: Patients exposed to wet work, such as hairdressers, may develop erythema, scaling, vesicles or erosions on the backs of their hands with repeated exposures. Hardening of the skin occurs after healing, and the prognosis is generally good. If exposures are not decreased however cumulative ICD may develop.

(iv) Subjective or Sensorial Irritation: Contact with an irritant produces a sensory discomfort, usually manifesting as a stinging, burning or itchy sensation, in the absence of clinical and histological (the structure of cells) evidence of skin lesions. The threshold to develop this reaction varies between people. Lactic acid and propylene glycol are good examples of subjective irritants. The outcome from this irritant reaction is good.

(v) Non-erythematous Irritation: This subtype refers to irritation of the skin which shows some pathologic changes but the skin looks normal ${ }^{\mathbf{9}}$.The symptoms are similar to those of subjective irritation. Individuals experience discomfort with many chemicals. This form is believed to commonly occur with exposure to consumer products that have a high content of surfactants, such as cocamidopropyl betaine. The prognosis is variable. This subtype of ICD is suggested to play a role in people who develop "sensitive skin". Both neural and vascular components, contribute to the discomfort.

(vi) Cumulative Irritant Contact Dermatitis: This is the most prevalent type of ICD. It is the result of multiple subthreshold insults induced by weak irritants. The repetitive nature of the irritants does not allow the skin to recover leading to persistent dermatitis or chronic dermatitis. The clinical features include redness and dryness followed by a thickening of the skin called hyperkeratosis. The threshold varies again between individuals. It is very important to remember that with Cumulative ICD the symptoms do not occur immediately after the exposure. This is similar to Allergic Contact Dermatitis (ACD) and therefore the two often cannot be distinguished without the help of 
Patch Testing. Another very important point is that exposure to weak irritants occurs not only at work, but also at home, adding to the complexity of identifying contributing factors.

(vii) Traumatic Irritant Contact Dermatitis: This is an uncommon form of ICD. It occurs after a very acute or sudden exposure to an irritant similar to a chemical burn. It is characterized by incomplete healing of the original insult followed by a nummular or circular eczema-like lesion. It has a chronic course and is sometimes recalcitrant (stubbornly resistant) to therapy 10

(viii) Pustular and Acneiform Dermatitis: Exposure to metal, tars, oils and chlorinated agents can result in a pustular (relating to small, circumscribed elevation of the skin, containing purulent material) and acne form (resembling acne) dermatitis especially in atopic (allergic) patients (patients with Atopic Dermatitis, Hay fever and or Asthma).

(ix) Frictional Dermatitis: Frictional Dermatitis is caused by a shearing force acting horizontally to the surface, rather than pressure or temperature. It can be defined as an eczematous process in which physical frictional trauma contributes to the cause of a dermatitic process. It is confined to the locations of frictional trauma. It is common on the hands, especially the dominant hand, but can occur anywhere on the skin where repetitive frictional forces occur. It is underdiagnosed due to the lack of recognition of the potential for physical friction to induce eczematous changes in the skin. Repetitive friction can produce redness, scaling, occasionally vesicles (small, circumscribed elevation of the skin containing fluid.) and hyperkeratosis (thickening of the skin) and fissures or cracks in the skin. These changes are most common on the fingers especially the sides and tips as well as the palms. It is often delayed in onset sometimes by years. Published occupations associated with Frictional Hand Dermatitis include repetitive handling of small metal components, paper, plastic, cardboard, fabric and driving $\mathbf{1 1}$.

Prognosis usually is good. Cases of Frictional Dermatitis improve once removed from the friction. However, in an occupational setting, modification of the job to decrease frictional forces cannot always be accomplished. Protective Equipment, in particular gloves, are an important treatment consideration and one where more study needs to be done. Gel Impaction Gloves have shown some promise at prevention of shearing frictional impact on the skin and improvement of Frictional Hand Dermatitis on the job ${ }^{\mathbf{1 2}}$.

(x) Hyperkeratotic Hand Dermatitis: Hyperkeratotic Hand Dermatitis can be classified as a subtype of ICD but irritation does not always have to be a precipitating event. It was found in two different studies to represent about $2 \%$ of all hand dermatoses ${ }^{13}$. It is most common in males aged 40-60. This condition is clinically similar to Frictional Hand Dermatitis and is characterized by hyperkeratotic plaques symmetrically on the proximal or middle parts of the palms and/or soles. Itch can be a factor and painful fissures usually develop. There is usually an absence of psoriatic (eruption of reddish, silvery-scaled round flat raised skin) nail or scalp changes. Over $50 \%$ of patients who develop Hyperkeratotic Hand Dermatitis have hard manual work at the time of onset. It has been postulated that chronic mechanical trauma contributes to the cause. The occupations associated included construction workers, forest workers, machinists, mechanists and paper handlers. Prognosis is very poor. Unlike patients who suffer from Frictional Hand Dermatitis these patients do not improve once removed from work environment and often have permanent disability.

\section{Patho-Physiology of Irritant Contact Dermatitis (ICD)}

ICD is most commonly known to be a non-specific immunologic response. However, as mentioned the immune system is felt to now play a role. A genetic polymorphism shown in ICD may lead to a novel approach to detect susceptibility to ICD ${ }^{\mathbf{1 4}}$. Essentially, a chemical irritant or toxin damages the keratinocyte. The keratinocyte is the main cell in the outermost layer of the skin, the epidermis. This damage induces the activation of inflammation mediators. These mediators turn on genes in the keratinocyte which result in the production of proteins. These proteins called cytokines (proteins derived from cells) activate the immune system in the skin, in particular the T cells. All of these mediators and cells result in dilation (opening) of blood vessels in the area. This results in swelling and infiltration of more inflammatory and immune cells to the area.

\section{ALLERGIC CONTACT DERMATITIS (ACD)}

Allergic contact dermatitis is caused by a wide range of chemicals (potential allergens) after prolonged or repeated contact with the skin. It is less common than ICD and is estimated to cause about $20 \%$ of occupational skin disease. Its prevalence in Europe is about $20 \%$ of the population; the most common allergens are nickel, fragrances and preservatives. The most frequently and consistently reported agents in cases of allergic occupational contact dermatitis include cobalt, chromates, cosmetics and fragrances, epoxies, nickel, plants, preservatives, resins and acrylics ${ }^{15}$. ACD is an adaptive immune response toward chemicals penetrating the skin. It is a type IV, delayed or cellmedicated immunological reaction. In common with other forms of allergy, ACD occurs in a two phase process. Sensitization occurs on the initial exposure to the chemical resulting in immunity to the allergen followed by elicitation on re-exposure. If exposure to the specific allergen (chemical substance) is most likely to occur in an occupational setting, then the resulting dermatitis is considered to be work-related. Most importantly, in ACD most contact allergens produce a sensitizing allergic reaction in only a small percentage of exposed individuals, unlike ICD. Numerous factors may contribute to the allergen sensitization including temperature, humidity, genetic predisposition, and previous or concurrent skin irritation. The most important factor in an individual has been shown to be recent or present skin damage from trauma or irritation at the site of contact of the potential allergen. This often 
explains why some workers have minimal skin issues for months to years then "suddenly" develop an allergic contact dermatitis.

ACD is a specific immunologic response. This is also called an adaptive immunological response. Adaptive immunologic responses are classified into 4 Types, based on the Gel and Coombs classification. ACD is a type IV delayed hypersensitivity immunologic response.

\section{Classification of Hypersensitivity}

(i) Immediate hypersensitivity

It includes three types:

- Type I (anaphylactic hypersensitivity). It involves IgE, mast cells, basophils and mediators that induce muscle contraction. This would manifest as urticaria, angioedema and anaphylaxis (shock).

- Type II (cytotoxic hypersensitivity). It involves IgG, IgM, complement, and the destruction of host cells.

- Type III (immune complex hypersensitivity). It involves $\mathrm{IgG}$, IgM, complement, and the formation of antigen-antibody aggregates in the tissues.

(ii) Delayed hypersensitivity

- Type IV (cellular hypersensitivity). It involves lymphokines and T-lymphocytes.

This is seen in Allergic Contact Dermatitis. ACD is mediated by $\mathrm{T}$ cells and not antibodies. The response occurs in two phases, initially a sensitization and then an elicitation response.

Sensitization: An allergen which is a chemical of low molecular weight is applied to the skin. The allergen is then taken up by a cell in the skin/epidermis called the Langerhan cell.

This cell then presents the allergen to the immune system in the skin, the $\mathrm{T}$ cell. The presence or absence of specific $\mathrm{T}$ cell in the skin is most likely genetically determined. Once the allergen is recognized by the $T$ cell both cells are activated and mediators are produced which leads to an increase in $\mathrm{T}$ cell proliferation. An expansion of specific $\mathrm{T}$ cell clones is produced. These $\mathrm{T}$ cell clones or memory cells recognize this allergen. The individual is now sensitized or primed to respond when these circulating $\mathrm{T}$ memory cells are exposed to the antigen.

Elicitation Phase: The second phase or elicitation of the delayed type of hypersensitivity occurs on reexposure. The allergen is applied to the skin and the Langerhan cells present it to the immune system in the skin. The primed or memory $\mathrm{T}$ cells become activated and are produced in greater numbers. Inflammatory mediators are produced, vessels dilate and swelling in the area occurs as well as infiltration of more cells.

\section{Common causes of ACD}

Metals: Nickel is the most common cause of ACD in women in almost all countries. The greater exposure of women to high-nickel content jewelry is a predisposing factor. Ear piercing is considered to be the principal inducer of nickel contact dermatitis. Hand eczema in nickel sensitive patients is often of the dyshidrotic type and may be aggravated by nickel ingestion. A threshold of 0.5 microgram of nickel $/ \mathrm{cm} 2 /$ week has been established to which only a small number of nickelsensitive patients will react ${ }^{\mathbf{1 6}}$. The Danish nickel exposure regulation and the nickel directive (European Union) regulating nickel content in objects which are in direct and prolonged contact with the skin have resulted in a significant decrease in nickel sensitization in young patients 17,18 .

Chromate is the most common contact allergen in men and sensitization to it is usually occupational. Occupational exposure is most frequent in construction workers who handle cement. Other common sources are chrome-tanned leather, bleaching agents, paints, and printing solutions.

Cosmetics and skin care products: Compulsory ingredient labeling of cosmetic products (excluding perfumes) has greatly facilitated the diagnosis and treatment of cosmetic contact dermatitis. Positive patch tests are found most frequently to preservatives, perfumes, active or category-specific ingredients, excipients/ emulsifiers and sunscreens ${ }^{19}$. The relevance of the positive patch tests is confirmed if the contact dermatitis disappears upon discontinuation of the use of the product. Most allergic reactions are caused by cosmetics that remain on the skin: "stay-on" or "leaveon" products ${ }^{20}$.

Dermatitis from clothes and shoes: Contact dermatitis to clothes is usually located in the axillae, which is due to the release of allergens from the textile under the action of sweat and friction. Clothing dermatitis from formaldehyde is rare nowadays. Textile dye dermatitis is usually related to disperse dyes ${ }^{\mathbf{2 1}}$. Leather articles contain several substances that may cause ACD: chrome, adhesives (paratertiary butyl phenol formaldehyde resin), and dyes. Anumber of accelerators and antioxidants used in the production of synthetic rubber may also cause contact dermatitis.

Drug dermatitis: Drug dermatitis may be elicited by the active ingredient of a topical drug, by the vehicle or by a preservative. Contact sensitization to antibiotics, antiseptics, and anesthetics is relatively frequent, especially in leg ulcer patients. ACD from topical corticosteroids has been reported with increasing frequency ${ }^{22,23}$. Systemic application of a drug to which an individual has been sensitized by a previous cutaneous exposure may cause systemic contact dermatitis.

Plant dermatitis: Plant dermatitis can manifest itself in a variety of ways, depending upon the plant and the means of exposure. Airborne contact dermatitis mimicking photodermatitis may be caused by sesquiterpene lactones found in the Compositae family, while contact dermatitis to plants from the Liliaceae and Alstroemeriaceae families may present as a dry painful dermatitis of the fingers in bulb growers, called "tulip fingers". Urushiol, present in poison ivy and poison oak is the most common cause of ACD in the United States, with $50 \%$ of the adult population clinically sensitive to it. 


\section{Histopathology of ACD}

The histopathologic findings are different in acute and chronic contact dermatitis and are dependent on the severity of the inflammatory reaction. The most common histologic feature is spongiosis, which results from intercellular edema. It is often limited to the lower epidermis but, if the reaction is severe, it may affect the upper layers. The clinical expression of intense fluid accumulation in the acute stage is the formation of vesicles that may rupture at the epidermal surface. The papillary vessels are dilated, with perivascular lymphohistiocytic infiltrate, and the upper dermis is edematous. The lymphohistiocytic infiltrate extends in the epidermis (exocytosis) and accumulates in the spongiotic vesicles. In subacute and chronic ACD the spongiotic pattern gradually fades out, the epidermis becomes hyperplastic, and parakeratosis develops.

\section{Treatment of ACD}

The only available etiologic treatment of ACD is elimination of the contact allergen. The patients should be informed about the identity of the offending agent and the possible sources of the sensitizer. Cross-reacting substances should be listed. Topical steroids are used in the acute stage and are gradually replaced by ointments and cold creams as the skin lesions withdraw. If ACD is widespread and severe, systemic corticosteroids may be indicated for a short period of time. Reducing the total body load of nickel has been attempted in nickel eczema by means of a nickel-restricted diet and by treatment with disulfiram. Trials have yielded conflicting results as regards the clinical effect of the treatment and the application of the metal-chelator disulfiram was limited by serious side effects ${ }^{24}$. Oral hyposensitization to urushiol and nickel has been attempted but is not performed in practice. Conventional immunosuppressive therapy is not appropriate in the management of ACD. New immunomodulating macrolactams have been successfully tested in clinical trials ${ }^{\mathbf{2 5}, \mathbf{2 6}, \mathbf{2 7}}$. Perspectives in pharmacological intervention include new classes of immunosuppressors, inhibitors of cellular metabolic activity, inhibitors of cell adhesion molecules, targetted skin application of regulatory cytokines and neutralization of pro-inflammatory cytokines (antisense oligonucleoides, anticytokine antibodies, soluble cytokine receptors).

\section{Patho-physiology ACD}

Although ICD is not allergen specific and ACD is allergen specific the end result of both from a cellular level is similar. There is activation of immune $\mathrm{T}$ cells in the skin and inflammation resulting in dermatitis clinically in the skin.

\section{(i) Endogenous Factors:}

Endogenous factors can influence the susceptibility to ICD and ACD.

\section{ACD}

- $\mathrm{ACD}$ is somewhat less common in young children however a recent increase in documentation of ACD cases in children is being seen.
- $\mathrm{ACD}$ requires a specific immune response to the allergen presented on the skin.

- The presence or absence of specific $\mathrm{T}$ cells in the skin is most likely genetically determined.

- Concurrent dermatitis of the skin is known to increase the risk of sensitization to a potential allergen, therefore patients who have suffered from Atopic Dermatitis in the past or present are more susceptible to sensitization by allergens.

- Mucosal Atopy which includes Asthma and Hay fever does not have such a clear cut impact on the susceptibility to potential allergens applied to the skin.

ICD

- Susceptibility to skin irritation decreases with age.

- CD appears to be more common in women, It is not clear if this is due to an increased susceptibility to ICD in women or greater exposure of women to irritants, in particular wet work. Further studies need to be done.

- Skin penetration varies with anatomic region. The face is the most permeable; it

- $\quad$ is three times more permeable than the back.

- Patients with altered barrier skin function are more prone to ICD. Existing dermatitis, regardless of type, enhances reactivity to various irritants in areas of body not already involved with dermatitis ${ }^{28}$. This is very clear for atopic dermatitis.

(ii) External/Exposure Factors:

Irritant Contact Dermatitis can be caused by various irritants including chemicals and physical or mechanical irritants. The potential for irritancy of a substance is determined by its chemical and physical properties. The size, ionization and fat solubility determine skin penetration. Chemicals that are mild irritants will require repeat exposure. At high levels of exposure, many chemicals will act as irritants. The concentration, volume, application length and duration of exposure on the skin will determine the outcome. The penetration of an irritant will increase with exposure volumes and duration of exposure. This often comes into play with workers who work long hours over few days such as 3 days on and 4 days off which would increase the likelihood of developing ICD as the volume and duration of exposure would be increased with this type of shift.

\section{(a) Skin Irritants:}

Almost all chemicals have the potential to cause ICD. Identifying one cause is often not possible. The most important and common skin irritant is wet work ${ }^{29}$. Wet work is defined as the exposure of the skin to liquid for longer than 2 hours per day, the use of occlusive gloves for longer than 2 hours per day or frequent hand cleaning ${ }^{30}$. Occupations at risk include hairdressers, food handlers and health care workers. Wet work is the most common skin irritant followed by exposures to soap, detergents, solvents and oils and acid or alkali substances. 


\section{(b) Physical or Environmental Skin Irritants ${ }^{31}$}

Low Humidity: Low environmental humidity enhances skin irritation. Air that is warm, dry and mobile can cause itch and even eczematous changes. Air conditioning results in low humidity in the workplace. An example is Airline stewardesses, particularly those on long haul flights. They give a history of recurrent facial eruptions that improve away from the air conditioned environment of the aircraft cabin.

Heat: Heat leads to sweating and is a particular problem from those working in a factory environment. Examples include workers close to welding equipment, molten metals and glass or those working close to furnaces or incinerators. Many of these patients suffer from facial dermatitis. Sweating can also facilitate the skin penetration of allergens. Heat, sweat and occlusion of gloves or clothing can cause irritation.

Metal Materials: Chronic and repeated exposure to metal material handled by employee's results in Frictional Hand Dermatitis. The dominant hand and fingers are the most commonly affected sites. Metal shavings and dust can also produce a facial dermatitis.

Paper: The majority of workers exposed to paper as a physical irritant work in offices, post offices and banks. The repeated sifting and distribution of paper cause friction and dryness of the finger pulps leading to chronic dermatitis.

Tools: Chronic low-grade trauma and friction to the hands from the use of tools can cause a variety of ICD responses. Workers from manufacturing, construction, woodworking, maintenance and repair industries were particularly affected. The hands are the most common site in these occupations. The mechanisms of irritation were usually friction and chronic trauma.

Fabrics: Repeat handling of fabrics by workers in the textile industry cause friction and desiccation (dryness) particularly to the hands. The fabrics commonly included implicated include polyester, nylon and wool. Repeat handling of fabric sacks by warehouse workers can be a problem. The fiber friction, rigidity and fineness all contribute to the increased risk of cutaneous irritation.

Plastics: Repeat handling of small plastic objects or bags can cause Frictional Hand Dermatitis. Plastic dusts can be generated by filing-down and finishing which can lead to facial ICD.

Dusts: Dusts can be produced by airborne particulate matter from wood, metals, plastics, cement and plaster. The dusts often spread over considerable distances to affect individuals not close by or immediately involved in the process. Workers commonly affected include carpenters and builders. Mechanical friction from sanding down these materials often causes chronic dermatitis on the hands and the resulting dust causes dermatitis on the face.

Wood Materials: Friction from handling unfinished wood products in the carpentry and construction industry can lead to Frictional hand dermatitis.
Rubber: Rubber bands are widely used in office and warehouses. Workers can develop dermatitis on their dominant hand. Rubber used in the grips of sports rackets can lead to a hobby-related or aggravated friction and pressure on the palms.

Heavy Machinery: Machine operators in factories often have to manipulate heavy pieces of equipment repeatedly, often as part of assembly work. This can result in repetitive mechanical trauma to the hands from heavy physical work and then frictional hand dermatitis.

Fiberglass: Fiberglass is a manufactured fiber made from silicon dioxide with various metals and other elements. Fiberglass can cause folliculitis, and irritant symptoms including itching without rash, burning of eyes, sore throat and cough. Curiously, not all workers are affected suggesting an individual predisposition. Fiberglass over a diameter of 3.5 ppm (parts per million) causes tissue irritation. Dermatitis usually occurs on exposed body sites due to contact with fiberglass dusts produced by grinding, sawing, and finishing. ACD can also occur to chemicals added to fiberglass manufacturing and should be ruled out in new onset cases of dermatitis.

Allergic Contact Dermatitis is caused by chemicals known as allergens. Allergens are small molecules that bind to carrier proteins in the skin. Several factors can contribute to allergen sensitization and include increased temperature, humidity and previous or concurrent skin irritation. ACD develops with repeat exposure to chemical allergens. Workers may contact a potential allergen many times over many months without any problems and then suddenly become sensitized and develop intractable ACD. Elicitation of ACD in sensitized workers will depend on the duration and frequency of exposure, region of application and the presence of irritants. It is not possible to discuss all the potential chemical allergens associated with ACD. Textbooks in Occupational Dermatology usually break down potential irritants as well as allergens by occupation and discuss both within each occupation. However, discussion of the common allergen chromium will help illustrate the role of the allergen, exposure parameters, how it relates to the development of ACD and possible control measures.

Chromium: Chromium is a steel gray hard metal. It is used in metal alloys (stainless steel is an example), plating, leather tanning, paint, anticorrosives, ceramics and chemicals.

Historically the most important cause of contact allergy to chromium has been occupational exposure to cement. Two forms of chromium act as allergens; these include Trivalent Chromium and Hexavalent Chromium. The existence of each depends on the $\mathrm{pH}$ and temperature of the cement. Cases of ACD to chromium in cement date back to 1908 and 1925. Patch testing with Potassium dichromate $0.5 \%$ in petrolatum is used to diagnosis ACD to chromium. In 1950 it was determined that the Hexavalent Chromium allergen was the main cause of ACD from cement. In 1979, it was suggested that the addition of iron sulfate to cement would reduce the amount of water soluble Hexavalent Chromium in 
cement to 2 ppm. In Denmark in 1983, legislation was passed that made addition of iron sulfate to cement compulsory. Since then in Denmark the prevalence of ACD to chromium among construction workers have decreased. In countries, including Canada that did not pass this legislation chromium continues to cause ACD in construction workers. The European Union on January 17, 2005, restricted the marketing and use of cement containing more than $2 \mathrm{ppm}$ hexavalent chromium $^{32}$.

\section{CONCLUSION}

Dermatitis was estimated to affect 245 million people globally in 2015. Atopic dermatitis is the most common type and generally starts in childhood. The cause of dermatitis is unknown but is presumed to be a combination of genetic and environmental factors. Diagnosis of dermatitis is based mostly on the history and physical examination. In uncertain cases, skin

\section{REFERENCES}

1. Bos JD. The skin as an organ of immunity. Clin Exp Immunol. 1997; 107(1):3-5.

2. British Association of Dermatologists Patient Information Leaflet, 2007.

3. Kadyk DL, McCarter K, Achen F. Quality of life in patients with allergic contact dermatitis. J Am Acad Dermato. 2003,; 49(6): 1037-1048.

4. Burneet CA, Lushniak BD, McCarthy W, Kaufman J. Occupational dermatitis causing days away from work in U.S. private industry. Am J Ind Med, 1998; 34(6):568-573.

5. www.ccohs.ca

6. Weltfriend S, Michal R, Howard IM. Irritant dermatitis (irritation). In Dermatotoxicology, edited by Hongbo Zhai and Howard I. Maibach, Boca Raton: CRC Press, 2004; 181-228.

7. Slodownik DA, Adriene L, Rosemary N. Irritant Contact Dermatitis: a review. Australasian Journal of Dermatology, 2008; 49:1-11.

8. Malten KE, Arend den JACJ, Wiggers RE. Delayed irritation: Hexanediol diacrylate and butanediol diacrylate. Contact Dermatitis, 1979; 5:178- 184.

9. Charbonnier V, Morrison BM, Paye M, Maibach HI. Subclinical, non-erythematous irritation with an open assay model (washing): sodium laurel sulfate (SLS) versus sodium laureth sulfate (SLES). Food Chem Toxicol, 2001; 39(3):279286.

10. Mathias CG. Post-traumatic eczema. Dermatol Clin, 1988; 6(1):35-42.

11. McMullen E, Gawkrodger DJ. Physical Friction is underrecognized as an irritant that can cause or contribute to contact dermatitis. British Journal of Dermatology, 2006; 154(1):154-156.

12. Kwok T, Victoria A, Sandy SG. Repeated Mechanical Trauma to the hands: The use of anti-impaction gloves for treatment and return to work. Dermatitis, 2009; 20(5):278-283.

13. Meding B, Swanbeck G. Epidemiology of different types of hand eczema in an industrial city. Acta Derm Venerol, 1989; 69:227-233.

14. Allen M, Sarah H, Wakelin H, Doris H, Steen L, Ole B, Jonathan NWN, Barker, John P. M. Association of TNFA gene polymorphism at position-308 with susceptibility to irritant contact dermatitis. Immunogenetics, 2000; 51(3):201-205.

15. Nicholson PJ, Dlewellyn D, English JS. Evidence-based guidelines for the prevention, identification and management of occupational contact dermatitis and urticaria. Contact Dermatitis, 2010; 63(4):177-186.

16. Menne T. Prevention of nickel allergy by regulation of specific exposures. Ann Clin Lab Sci, 1996; 26:133-8. biopsy may be useful. Patch tests are used in the diagnosis of allergic contact dermatitis. There is no known cure for some types of dermatitis, with treatment aiming to control symptoms by reducing inflammation and relieving itching. Contact dermatitis is treated by avoiding what is causing it. A number of monoclonal antibodies are being studied as treatments including dupilumab.

\section{Conflicts of interest}

The authors declare that they have no competing interests.

\section{Acknowledgements}

Authors are thankful to Truba Institute of Pharmacy and Sapience Bio analytical Research Lab. Bhopal, India for providing necessary facilities for the successful completion of work.
17. Jensen CS, Lisby S, Baadsgaard O, Volund A, Menne T. Decrease in nickel sensitization in a Danish schoolgirl population with ears pierced after implementation of a nickelexposure regulation. Br J Dermatol, 2002; 146:636-42.

18. Schnuch A, Geier J, Lessmann H, Uter W. Decrease in nickel sensitization in young patients--successful intervention through nickel exposure regulation? Results of IVDK, 1992 2001. Hautarzt, 2003; 54:626-32.

19. Goossens A, Beck MH, Haneke E, McFadden JP, Nolting S, Durupt G. Adverse cutaneous reactions to cosmetic allergens. Contact Dermatitis, 1999, 40, 112-3.

20. De Groot AC. Fatal attractiveness: the shady side of cosmetics. Clin Dermatol, 1998; 16:167-79.

21. Hatch KL, Maibach HI. Textile dye allergic contact dermatitis prevalence. Contact Dermatitis, 2000; 42:187-95.

22. Rocha N, Silva E, Horta M, Massa A. Contact allergy to topical corticosteroids 1995-2001. Contact Dermatitis, 2002; 47:362-3.

23. Corazza M, Mantovani L, Maranini C, Bacilieri S, Virgili A. Contact sensitization to corticosteroids: increased risk in long term dermatoses. Eur J Dermatol, 2000, 10, 533-5.

24. Veien NK, Hattel T, Laurberg G. Low nickel diet: an open, prospective trial. J Am Acad Dermatol, 1993; 29:1002-7.

25. Saripalli YV, Gadzia JE, Belsito DV. Tacrolimus ointment $0.1 \%$ in the treatment of nickel-induced allergic contact dermatitis. J Am Acad Dermatol, 2003; 49:477-82.

26. Ruzicka T, Assmann T, Lebwohl M. Potential future dermatological indications for tacrolimus ointment. Eur $\mathrm{J}$ Dermatol, 2003; 13: 331-42.

27. Marsland AM, Griffiths CE. The macrolide immunosuppressants in dermatology: mechanisms of action. Eur J Dermatol, 2002, 12, 618-22.

28. Nassif A, Sai C, Chan F, Storres J, Jon MH. Abnormal skin irritancy in atopic dermatitis and in atopy without dermatitis. Arch Dermato, 1994; 130(11):1402-1407.

29. Tupker RA. Prediction of irritancy in the human skin irritancy model and occupational setting. Contact Dermatitis, 2003, 49(2), 61-69.

30. Dickel H, Oliver K, Anne S, Judith Kret Z, Thomas LD. Importance of irritant dermatitis in occupational skin disease. American Journal of Clinical Dermatology, 2002: 3(4):283289.

31. Morris-Jones R, Robertson SJ, Ross JS, White IR, McFadden JP, Rycroft RJG. Dermatitis caused by physical irritants. British Journal of Dermatology, 2002; 147(2):270-275.

32. Official Journal of the European Union, 2003; 178/24-178/28. 